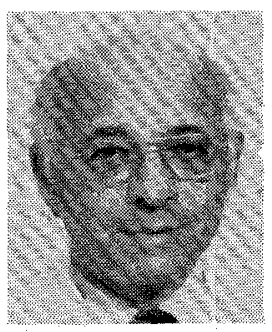

Sol M. Michaelson (SM'79) is a Professor of Radiation Biology and Biophysics and an Associate Professor of Medicine and of Laboratory Animal Medicine of the School of Medicine and Dentistry and is on the faculty of the Biomedical Engineering Program of the College of Engineering of the University of Rochester, Rochester, NY. His major research interests are physiologic and pathophysiologic aspects of electromagnetic radiation, having published over 150 papers in this field. He has been a Consultant and Advisor to the World Health Organization Regional Office for Europe for health effects on personnel of ionizing radiations and other physical factors. He has been a Consultant to the National Research Council, National Academy of Sciences, and a member ad hoc Committee of the Navy
Non-Ionizing Radiation Research Program and of the ad hoc Committee on Electrical Stimulation of the Brain, Commitee on Biosphere Effects of ELF Radiation, Consultant on National Research Council Commission on Human Resources' Post Research Associateship Program; member of Advisory Committee for Biological Effects of Electric Fields, Electric Power Research Institute, and American National Standards Institute, Committee C95, Radio Frequency Radiation Hazards. He is a Consultant to the US National Council on Radiation Protection and Measurements; Science Advisory Board, U.S. Environmental Protection Agency; Board of Scientific Counselers, National Institute of Environmental Health Sciences NIH/HEW. He is an Associate Editor for Radiation Research, member of the Editorial Board of the International Journal of Radiation and Environmental Biophysics, as well as an Associate Editor for Medical and Biological Sciences, the Journal of Microwave Power; editorial board - Bioelectromagnetics.

\title{
A High-Power Automatic Network Analyzer for Measuring the RF Power Absorbed by Biological Samples in a TEM Cell
}

\author{
JOHN R. JUROSHEK AND CLETUS A. HOER
}

\begin{abstract}
A device for measuring the radiofrequency (RF) power absorbed by biological samples while they are being irradiated in a transverse electromagnetic (TEM) cell is described. The report discusses the design, calibration, and performance of this automated measurement system. The power absorption analyzer is based on a six-port type of automatic network analyzer, and operates at an incident power to the TEM cell of 1 to $1000 \mathrm{~W}$, over a frequency range of 100 to $1000 \mathrm{MHz}$. Experiments show that an absorbed power of 0.02 to 0.05 percent of the incident power can be measured. Measurements of the power absorbed by a 1-percent saline solution were made using the power absorption analyzer and by an indepen dent calorimetric measurement. The two measurement techniques show excellent agreement.
\end{abstract}

Key Words - Automatic network analyzer, biological effects, impedance measurements, power absorption analyzer, power measurements, six-port network analyzer, and TEM cell.

\section{INTRODUCTION}

$\mathrm{T}$ HIS REPORT describes an RF power-absorption analyzer developed by the National Bureau of Standards for the National Institute for Occupational Safety and Health. The analyzer is designed specifically to measure the power absorbed by biological samples while they

Manuscript received October 12, 1983; revised March 9, 1984. This work was supported by the National Institute for Occupational Safety and Health.

The authors are with the U.S. Department of Commerce, National Bureau of Standards, 724.01, 325 Broadway, Boulder, CO 80303. are being irradiated with continuous-wave RF energy in a transverse electromagnetic (TEM) cell. The analyzer is based on a six-port automatic network analyzer which makes it possible to detect very small amounts of absorbed power [1]-[3]. Typically, the incident power to the TEM cell is of the order of 1 to $1000 \mathrm{~W}$ over a frequency range of 100 to $1000 \mathrm{MHz}$. The goal of the power absorption analyzer is to be able to detect absorbed power levels of the order of 0.05 percent of the incident power $(0.002 \mathrm{~dB}$ in insertion loss). Some of the problems typically encountered in making these measurements are discussed in a publication by Hill [4].

\section{THEORY}

A simple expression for the RF power absorbed by any biological sample irradiated in a TEM cell is derived as follows. Referring to Fig. 1 for a definition of terms, the RF power absorbed by the empty cell can be written

$$
P_{\text {cell }}=P_{1}-P_{L}=P_{1}(1-\eta)
$$

where

$$
\begin{aligned}
P_{1}= & \text { net power into the empty TEM cell measured at the } \\
& \text { input to the TEM cell, } \\
P_{L}= & \text { net power into the load measured at the output of } \\
& \text { the TEM cell, } \\
\eta= & P_{L} / P_{1}=\text { efficiency of the empty TEM cell. }
\end{aligned}
$$




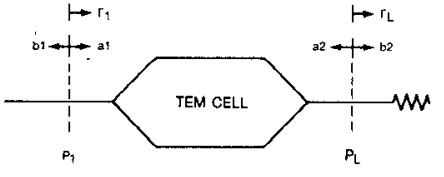

Fig. 1. TEM cell measurement parameters.

When the sample is placed in the cell, the power absorbed by the sample and the cell is given by

$$
P_{\text {cell }}^{\prime}+P_{\text {sample }}=P_{1}^{\prime}-P_{L}^{\prime}=P_{1}^{\prime}\left(1-\eta^{\prime}\right)
$$

where the prime indicates measurements with the sample inserted. Equation (1) shows that the power absorbed by the cell is proportional to $P_{1}$. When $P_{1}$ changes to $P_{1}^{\prime}, p_{\text {cell }}$ changes to

$$
P_{\text {cell }}^{\prime}=P_{1}^{\prime}(1-\eta) \text {. }
$$

Solving (2) and (3) for the power absorbed by the sample yields

$$
P_{\text {sample }}=P_{1}^{\prime}\left(\eta-\eta^{\prime}\right) \text {. }
$$

A general equation for the efficiency of any 2-port is given by Kerns and Beatty [5] as

$$
\eta=\frac{P_{L}}{P_{1}}=\left|\frac{b_{2}}{a_{1}}\right|^{2} \frac{1-\left|\Gamma_{L}\right|^{2}}{1-\left|\Gamma_{1}\right|^{2}}
$$

$\Gamma_{L} \quad=$ reflection coefficient of the load as seen

from the output port,

$\Gamma_{1} \quad=$ reflection coefficient looking into the

empty TEM cell,

$b_{2} / a_{1}=$ ratio of the voltage wave emerging from the cell to

the voltage wave incident on the cell.

A similar expression with primes gives $\eta^{\prime}$. The power absorption analyzer measures $P_{1}^{\prime}$ and all of the quantities in (5) to determine $\eta$ and $\eta^{\prime}$. The power absorbed by the sample is then calculated from (4). These equations assume that the power absorbed by the empty cell does not change when the sample is inserted.

\section{SYSTEM DESCRIPTION}

There are undoubtedly many methods for making the measurements described in (4) and (5). The choice of a six-port network analyzer was based on a number of considerations. One reason was the data supporting its ability to make accurate, repeatable measurements [6]. Another consideration was the requirement to accurately calibrate the system from existing standards as will be discussed later. Simplicity of design, cost, and availability of hardware were also factors. Perhaps a slightly more obscure reason in favor of the six-port analyzer was the available redundancy that makes it easier to detect some types of malfunctions and to determine when the system is out of calibration.

A block diagram of the power absorption analyzer is shown in Fig. 2. Basically, the high-power RF signal is coupled to transfer switch $\mathrm{T} 1$, which directs the signal to

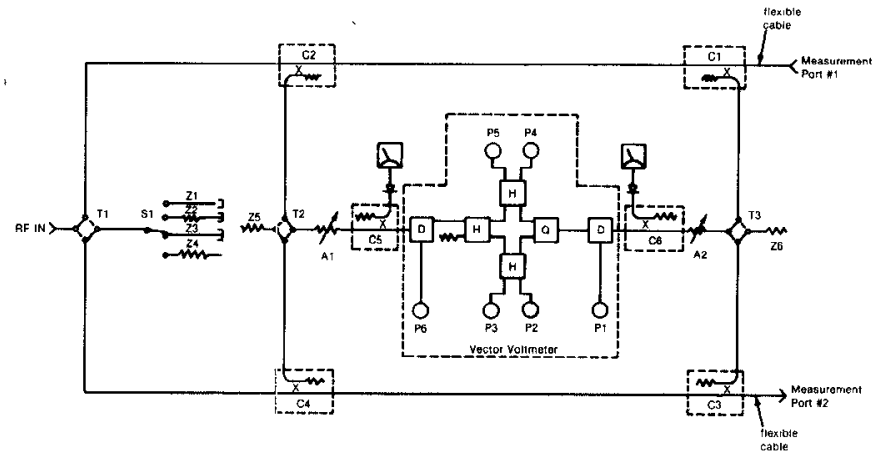

Fig. 2. Bilock diagram of measurement system.

either measurement port 1 or port 2. High-power, 30-dB couplers $\mathrm{C} 1, \mathrm{C} 2, \mathrm{C} 3$, and $\mathrm{C} 4$ divert part of the signal to transfer switches $\Pi[2, \mathrm{~T} 3$, and the vector voltmeter portion of the system. Attenuators A1 and A2 are 10-dB step attenuators used for the low (below $20 \mathrm{~W}$ ), medium (20 to $200 \mathrm{~W}$ ), and high ( 200 to $1000 \mathrm{~W}$ ) power ranges. Couplers $\mathrm{C} 5$ and $\mathrm{C} 6$ are $10-\mathrm{dB}$ couplers which, along with the diode detectors and meters, provide a visual indication of the RF power. Loads Z1, Z2, Z3, and Z4 are used in the calibration process and will be described in more detail later in the report.

Loads Z5 and Z6 are 50- $\Omega$ terminations. Fig. 3 summarizes the different system configurations possible during normal operation. In Fig. 3, $a_{1}, b_{1}, a_{2}$, and $b_{2}$ are the waves at measurernent ports 1 and 2 .

Referring to Fig. 2, the vector voltmeter portion of the system is comprised of two power dividers (D), three $180^{\circ}$ hybrids $(\mathrm{H})$, and one $90^{\circ}$ hybrid $(\mathrm{Q})$. These hybrids and power dividers provide six signals, $P_{1}$ through $P_{6}$, that are different combinations of the waves into the vector voltmeter. The signal at $P_{1}$ is primarily a function of the signal through C6, while $P 6$ is primarily coupled to the signal through C5. Detectors $P_{2}, P_{3}, P_{4}$, and $P_{5}$ are equally coupled to both signals into the vector voltmeter.

The magnitude of the six signals $P_{1}$ through $P_{6}$ is measured with thermistor power detectors. Accurate power measurements are made using power meters of the NBS, type IV design [7]. For the measurements shown in Fig. 3, only power detectors $P_{1}, P_{2}, P_{3}$, and $P_{4}$ are used. These detectors provide sufficient information, according to sixport theory, to calculate the complex ratios $a_{1} / b_{1}, a_{2} / b_{1}$, $a_{2} / b_{2}$, and $a_{1} / b_{2}$, as shown in Fig. 3. Power detectors $P 5$ and $P 6$ are used primarily as monitoring and debugging aids.

The analyzer is entirely automated and controlled by a desktop computer. The dc voltages from the type IV power meters are read into the computer using two commercial 6-1/2-digit voltmeters. Two volmeters are used here to reduce the effects of source-power fluctuations. Another major portion of the system is an automated commercial scanner used to switch the various components of the system.

The vector voltmeter portion of the analyzer, along with the thermistors, is packaged in a double-insulated, thermally controlled box. The inner portion of the box, contain- 


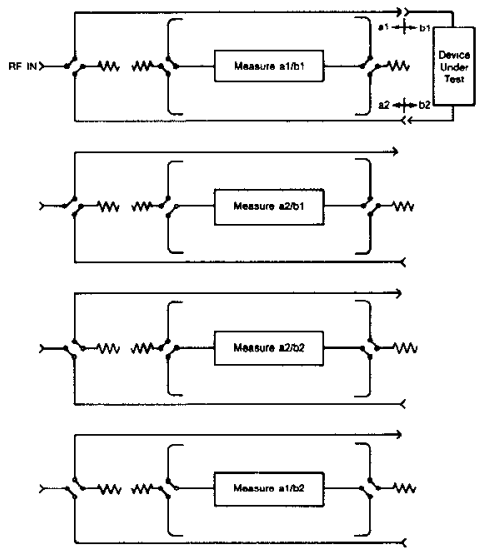

Fig. 3. System configurations for different measurements.

ing hybrids and thermistors, is maintained at a temperature of $37^{\circ} \mathrm{C}$ by a proportional temperature controller. The outer shell of the box, which is also insulated, is maintained at a temperature of $35^{\circ} \mathrm{C}$. These precautions were taken to minimize the day-to-day temperature dependency of the vector voltmeter. The day-to-day temperature variations at a monitor point inside the vector voltmeter are typically $0.05^{\circ} \mathrm{C}$ or less.

All of the system components cover the 100 to $1000-\mathrm{MHz}$ frequency band, except for high-power couplers $\mathrm{C} 1, \mathrm{C} 2$, C3, and C4. Unfortunately, only octave bandwidth couplers could be found that would satisfy the $30-\mathrm{dB}, 1000-\mathrm{W}$ requirements. Therefore, couplers $\mathrm{C} 1$ through $\mathrm{C} 4$ are manually switched into the system according to the frequency desired. Three sets of couplers (100 to $250 \mathrm{MHz}, 250$ to 500 $\mathrm{MHz}$, and 500 to $1000 \mathrm{MHz}$ ) are used to cover the decade frequency band. Measurements ports 1 and 2 are terminated in type $N$ female and male connectors, respectively.

\section{Calibration}

Details of calibrating the power absorption analyzer are beyond the scope of this paper; however, the system must be calibrated to make accurate power and complex impedance measurements. System calibration is particularly important since it accounts for imperfections such as the leakage around the high-power transfer switches and the finite-coupler directivity. Normally, directional couplers with a directivity of $50 \mathrm{~dB}$ are required to make the power absorption measurements with the accuracy desired [1]. With the six-port approach, couplers with 20-dB directivity are used, and the imperfections corrected with the calibration. The calibration procedure used here is a modification of the thru-reflect-line technique commonly used to calibrate dual six-port automated network analyzer [8].

One hundred separate measurements are required to calibrate the system. Most of these measurements are made automatically by the computer and do not require operator involvement. Fig. 4 outlines the seven basic operations that are visible to the operator.

Measurement port 1 is calibrated for accurate power measurements, as outlined in Fig. 4(a) and (b), by using a standard thermistor mount that has been accurately

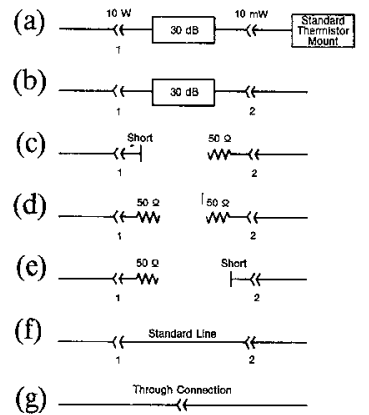

Fig. 4. Outline of steps required to calibrate the system.

calibrated by NBS for efficiency and reflection coefficient. The maximum input power to the thermistor mount is $10 \mathrm{~mW}$; however, accurate power measurements up to 10 W can be made by using a 30-dB attenuator whose scattering parameters are known. The scattering parameters of this attenuator are measured during the calibration process. Once measurement port 1 is calibrated to measure power, it can be used to calibrate the other measurement port. The power calibration is transferred to the higher power ranges using a "bootstrap" procedure as described in [3]. The estimated systematic error in measuring power is 3.2 percent for power measurements on the low range $(20 \mathrm{~W}), 3.7$ percent on the midrange $(20$ to $200 \mathrm{~W})$, and 4.2 percent on the high range (200 to $1000 \mathrm{~W})$. A significant portion of this error is due to a 1 percent error in the measurement of the efficiency of the standard thermistor mount by NBS, plus a 2-percent error in the measurement of $S_{12}$ of the 30-dB pad.

The analyzer is calibrated for accurate reflection coefficient measurements, as outlined in the steps shown in Fig. 4(c) through (g). In steps (c), (d), and (e), various combinations of shorts and $50-\Omega$ loads are connected to measurement ports 1 and 2. A male type $N$ short is connected to measurements port 1 , while a female type $N$ short is connected to port 2 . The reflection coefficient of the loads need not be known. The shorts are used to electrically establish the measurements ports, and are assumed to have a reflection coefficient of -1 .

A precision impedance standard is used to calibrate the analyzer for phase, reflection coefficient, and impedance measurements. This standard is a length of precision coaxial transmission line as shown in Fig. 4(f). Unlike a lossy standard, such as a 50- $\Omega$ termination, a coaxial line can be used at high power levels without significant changes in its parameters due to self heating.

The purpose of the four impedances $\mathrm{Z} 1$ (open), Z2 (3-dB attenuator + short), $\mathrm{Z} 3$ (short), and $\mathrm{Z} 4$ (50- $\Omega$ termination) is to provide four terminations with substantially different reflection coefficients. The reflection coefficients of these terminations also need not be known. The measurement data obtained by switching these terminations plus the connections to the various measurements ports are sufficient to characterize the power absorption analyzer and account for imperfections in components, such as the directional couplers and transfer switches. 


\section{System Performance}

Two different high-power RF generators were used to test the analyzer. The first of these, which covered the $100-220-\mathrm{MHz}$ frequency band, was an amplifier driven by a frequency synthesized signal generator. Its frequency was stable to within a few hertz, and its output power could be controlled by software commands from the ANA computer. The second generator, which covered the 220-850$\mathrm{MHz}$ frequency band, was a manually tuned high-power oscillator followed by a high-power amplifier. Its frequency had to be manually set, as did its output power. Frequency drifts of $\pm 50 \mathrm{KHz}$ were typical of this system. High-power bandpass filters were used on the output of both generators to reduce second and higher order harmonics. The attenuation of second-order and higher harmonics was greater than $50 \mathrm{~dB}$, relative to the fundamental.

One test of the analyzer was its ability to accurately measure the reflection coefficient $\Gamma$ of a short. For Figs. 5 and 6 , the reflection coefficient of a short was repeatedly measured over a 10-min period, at a frequency of 700 $\mathrm{MHz}$, and with an incident power to the short of $20 \mathrm{~W}$. The magnitude $|\Gamma|$ of the reflection coefficient is shown in Fig. 5, while the angle is shown in Fig. 6. As can be seen, the measurements were of the order of

$$
|\Gamma|=0.99986 \pm 0.00008
$$

and

$$
\text { Angle of } \Gamma=179.96 \pm 0.03 \mathrm{deg} \text {. }
$$

The change in the angle of $\Gamma$ with time was largely due to the expansion of the system's cables with increasing temperature.

Another check on the analyzer was to connect measurement ports 1 and 2 together and let the system measure the power absorbed at this junction, which ideally should be zero. Fig. 7 shows the results of such a test where the power absorbed at the junction is plotted as a function of time. The test frequency was $700 \mathrm{MHz}$ and the incident power was $20 \mathrm{~W}$. Over the 15 -h measurement period the system showed

$$
P_{\text {sample }}=0.004 \pm 0.008 \mathrm{~W}
$$

Thus, the average fractional error in measuring absorbed power is 0.02 percent $(0.004 \mathrm{~W}$ out of $20 \mathrm{~W})$. The long-term drift of the system was largely due to room temperature changes. Also, some of the cyclic behavior in the data was caused by the room's heating and cooling system, which was cyclic with a period of approximately $30 \mathrm{~min}$ or greater.

The power absorption analyzer was tested using a TEM cell $2 \mathrm{~m}$ long, $60 \mathrm{~cm}$ high, and $1 \mathrm{~m}$ wide. The manufacturer's specifications for the frequency response of this cell are dc to $250 \mathrm{MHz}$. However, care had to be exercised, in that undesirable propagation modes could be excited at certain specific frequencies above $174 \mathrm{MHz}$ [9]. A test frequency of $200 \mathrm{MHz}$, as used in this report, was above the first undesirable $\mathrm{TE}_{101}$ resonance that occurs near $184 \mathrm{MHz}$, and was therefore suitable for tests with the

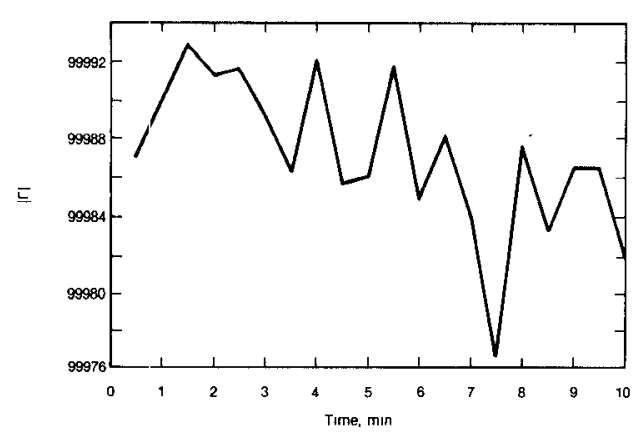

Fig. 5. Magnitude of reflection coefficient of a short versus time. Incident power to short is $20 \mathrm{~W}$, and frequency is $700 \mathrm{MHz}$.

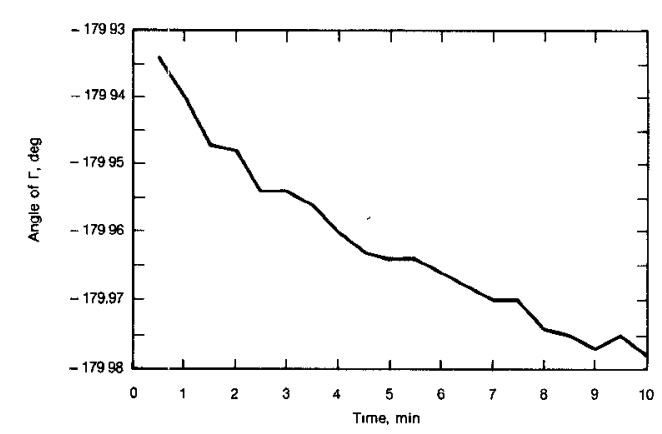

Fig. 6. Angle of reflection coefficient of a short versus time. Incident power to short is $20 \mathrm{~W}$, and frequency is $700 \mathrm{MHz}$.

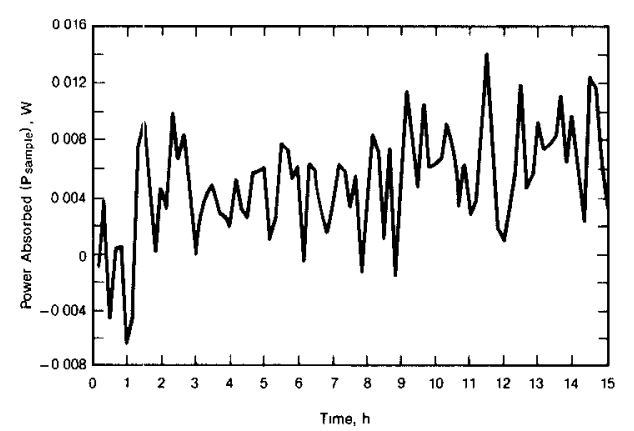

Fig. 7. Measurements of the power absorbed with measurement ports 1 and 2 connected together (thru connection), versus time. Incident power is $20 \mathrm{~W}$, and frequency is $700 \mathrm{MHz}$.

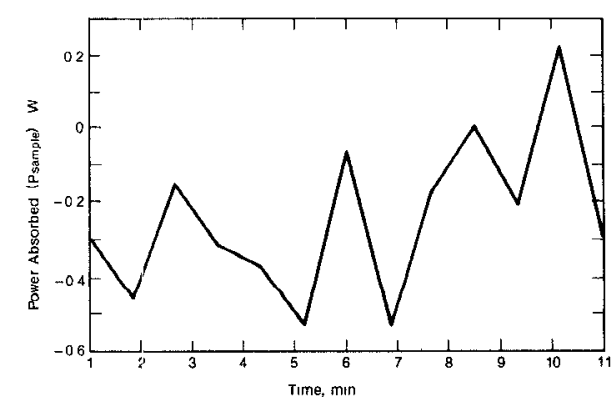

Fig. 8. Measurement of the power absorbed $\left(P_{\text {sample }}\right)$ with an empty TEM cell. Incident power to the TEM cell is $1000 \mathrm{~W}$, and frequency is $200 \mathrm{MHz}$ 
power-absorption analyzer. For the first measurement, the TEM cell was empty and the analyzer's ability to determine that $P_{\text {sample }}=0$ was tested. Fig. 8 shows a plot of $P_{\text {sample }}$ versus time for an 11-min period. The power incident to the cell $\left(P_{1}^{\prime}\right)$ during this test was $1000 \mathrm{~W}$ and the frequency $200 \mathrm{MHz}$. The tests showed

$$
P_{\text {sample }}=-0.25 \pm 0.4 \mathrm{~W}
$$

which results in an average fractional error of 0.025 percent $(0.25 \mathrm{~W}$ out of $1000 \mathrm{~W})$.

For the next set of tests, two plastic bottles of 1-percent saline solution, $300 \mathrm{~g}$ each, were inserted into the TEM cell. Each bottle was enclosed in a polyfoam insulated box with 1-in-thick sides. The incident power to the TEM cell was $500 \mathrm{~W}$ and the frequency $200 \mathrm{MHz}$. Fig. 9 shows a plot of the absorbed power versus time for a 90 -min test period. The sample was in the cell only during the periods $t_{1}$ to $t_{2}$, and $t_{3}$ to $t_{4}$. At all other times, the cell was empty. Ideally, the absorbed power should be zero when the cell is empty. Fig. 9, however, show that the empty cell measurements drift away from zero with increasing time. The maximum drift of the empty cell measurements was $1 \mathrm{~W}$ and was highly correlated with the change in temperature of the room housing the experiment. At least part of this drift was believed to be due to a change in the power absorbed by the $7.32-\mathrm{m}(24 \mathrm{ft})$ of $0.953-\mathrm{cm}(3 / 8 \mathrm{in})$ flexible cable that connected the TEM cell with the measurement system. A plot of the room temperature during the experiment is shown in Fig. 10. If the empty cell drift is subtracted from the measurements, then the power absorption of the sample is found to be $3.4 \mathrm{~W}$.

A graph of the magnitude $\left|\Gamma_{1}\right|$ of the reflection coefficient looking into the cell is shown in Fig. 11. The perturbations at $47 \mathrm{~min}$ into the test are caused by the operator. A plot of the incident power $P_{1}^{\prime}$ is shown in Fig. 12. The power absorption analyzer tried to maintain the incident power constant by adjusting the generator output power by software command. This "software power leveling" occurred approximately once per minute and was designed to remove the gross power changes caused by the amplifier drifting with temperature. With software leveling, the incident power remained constant to within 2-percent or better.

A check, as shown in Fig. 9, can be made on the measurements of absorbed power by using an independent calorimetric method [10]. The calorimetric method estimates the power absorbed by a 1-percent (by weight) saline solution to be

$$
W=\frac{69.77 w\left(T_{2}-T_{1}\right)}{\left(t_{2}-t_{1}\right)}
$$

where

$$
\begin{array}{ll}
W & =\text { net power absorbed by the solution, } \mathrm{W} \\
w & =\text { mass of solution, } \mathrm{kg} \\
\left(T_{2}-T_{1}\right) & =\text { temperature increase of solution, }{ }^{\circ} \mathrm{C} \\
\left(t_{2}-t_{1}\right) & =\text { elasped time of experiment, min. }
\end{array}
$$

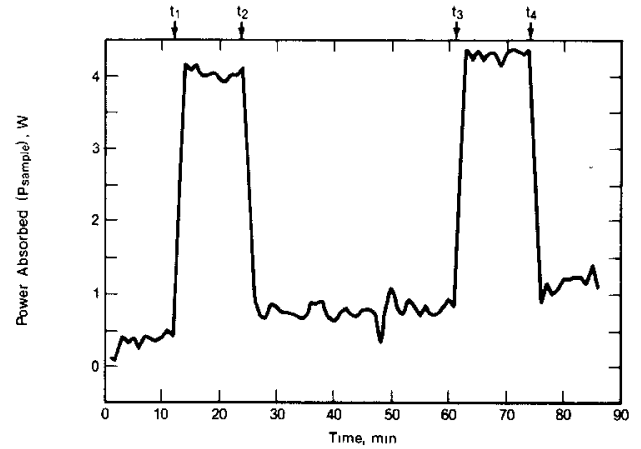

Fig. 9. Measurement of the power absorbed with 2 samples ( $300 \mathrm{~g}$ each) of 1-percent saline solution in the TEM cell versus time. Input power to the TEM cell is $500 \mathrm{~W}$, and frequency is $200 \mathrm{MHz}$.

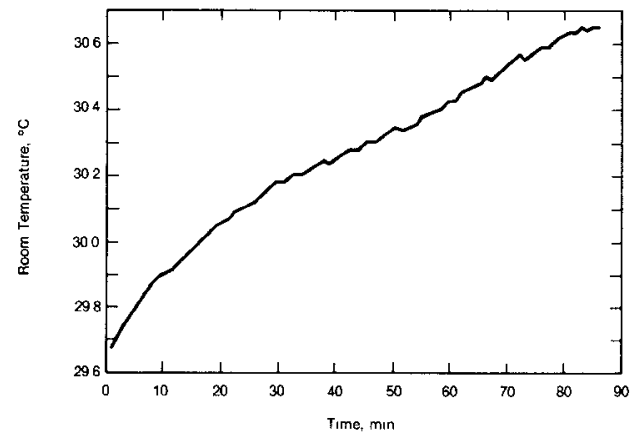

Fig. 10. Room temperature during the measurements shown in Fig. 9.

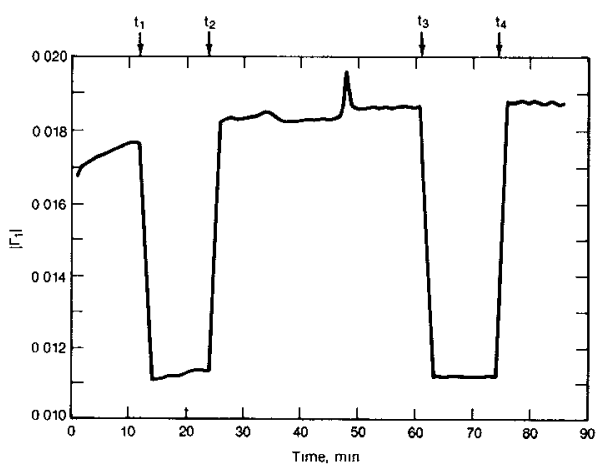

Fig. 11. Magnitude $\left|\Gamma_{1}\right|$ of the reflection coefficient, looking into the TEM cell during the measurements shown in Fig. 9.

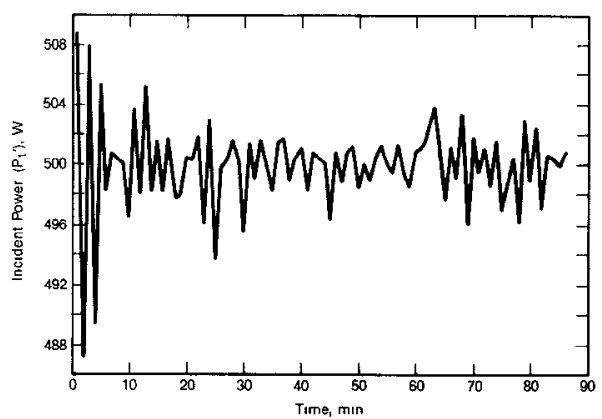

Fig. 12. Incident power to the TEM cell during the measurements shown in Fig. 9. 
TABLE I

Comparison of Absorbed PoWer MEASUREments Using THE POWER ABSORPTION ANALYZER AND CALORIMETRY

\begin{tabular}{ccc}
\hline Measurement Mumber & $\begin{array}{c}\text { Absorbed Power -as Measured } \\
\text { by the Analyzer (watts) }\end{array}$ & $\begin{array}{c}\text { Absorbed Power as Measured } \\
\text { by Calorimetry (watts) }\end{array}$ \\
\hline 1 & 3.6 & 2.4 \\
2 & 3.4 & 4.6 \\
3 & 3.6 & 3.9 \\
4 & 3.7 & 3.8 \\
\hline Averages & 3.6 & 3.7 \\
Std. Deviations & 0.13 & 0.92 \\
\hline
\end{tabular}

Measurements, such as shown in Fig. 9, were repeated on four different occasions. The agreement between power absorption measurements as made by the analyzer and calorimetry is summarized in Table $\mathbf{I}$.

The data shown in Fig. 9 are measurement number 2 in the table. It should be noted that the system drift, as evidenced by the nonzero $P_{\text {sample }}$ measurements when the TEM cell is empty, is subtracted from the data.

The averages of the four measurements using calorimetry and the power absorption analyzer agree to within $0.1 \mathrm{~W}$ $(3.7-3.6 \mathrm{~W})$. Since the incident power during the tests was $500 \mathrm{~W}$, the average fractional error was 0.02 percent. Unfortunately, there were a number of factors that lead to questions regarding this agreement. One problem, that was not discovered until after the tests had been made, was that the rubber stoppers used to seal the plastic bottles absorbed RF power. Subsequent tests showed that the power absorbed by those stoppers was about $1.4 \mathrm{~W}(0.7 \mathrm{~W}$ each). Since the solution was in contact with the stoppers, it was not known how much heat energy, if any, was transferred to the solution from the stoppers.

Also, the spread in the calorimetery data, as evidenced by the $0.9-\mathrm{W}$ standard deviation, showed the difficulty encountered in making repeatable calorimetry measurements.

In summary, the measurements show that an absorbed power on the order of 0.02 to 0.05 percent of the incident power can be measured with the power-absorption analyzer. To achieve this level of performance, the room housing the analyzer and TEM cell must be temperature stabilized to better than $1^{\circ} \mathrm{C}$, or alternately the effects of temperature change must be taken into account by periodically removing the test sample from the cell, so that changes in the power absorbed by the empty cell and connecting cables can be monitored.

\section{SUMMaRY}

A power absorption analyzer is described that makes accurate and repeatable measurements of the RF power absorbed by biological samples that are irradiated in a TEM cell. The analyzer operates over a power range of 1 to $1000 \mathrm{~W}$ and a frequency range of 100 to $1000 \mathrm{MHz}$. Experiments show that an absorbed power on the order of 0.02 to 0.05 percent of the incident power can be measured with the system. To achieve this level of performance, the temperature of the room housing the analyzer, cables, and
TEM cell must be temperature controlled to better than $1^{\circ} \mathrm{C}$. If the room is not temperature stabilized, then the biological sample must be periodically removed from the cell so changes in the power absorbed by the empty cell and connecting cables can be monitored. The estimated systematic error in measuring power is 3.2 percent on the low power range $(20 \mathrm{~W}), 3.7$ percent on the midrange (20 to $200 \mathrm{~W}$ ), and 4.2 percent on the high range ( 200 to $1000 \mathrm{~W}$ ). Test results show good repeatability in measuring the power absorbed by $300 \mathrm{~g}$ of 1-percent saline solution at $200 \mathrm{MHz}$ and $500 \mathrm{~W}$ to the cell. The average power absorbed as measured by the analyzer is $3.6 \mathrm{~W}$, with a standard deviation of $0.13 \mathrm{~W}$. This measurement is also in good agreement with measurements using calorimetery techniques, which estimated the absorbed power to be $3.7 \mathrm{~W}$.

\section{ACKNOWLEDGMENTS}

The authors are indebted to the contributions of A. Dudler and J. Yehle in assembling and testing the measurement system.

\section{REFERENCES}

[1] C. A. Hoer and K. C. Roe, "Using an arbitrary six-port junction to measure complex voltage ratios," IEEE Trans. Microwave Theory Tech., vol. MTT-23 pp. 978-984, Dec. 1975.

[2] G. F. Engen, "The six-port reflectometer: An alternative network analyzer," IEEE Trans. Microwave Theory Tech., vol. MTT-25, pp. 1075-1080, Dec. 1977.

[3] C. A. Hoer, "A high-power dual six-port automatic network analyzer used in determining biological effects of RF and microwave radiation," IEEE Trans. Microwave Theory Tech., vol. MTT-29, pp. 1356-1364, Dec. 1981.

[4] D. A. Hill, "Human whole-body radiofrequency absorption studies using a TEM-cell exposure system," IEEE Trans. Microwave Theory Tech., vol. MTT-30, pp. 1847-1854, Nov. 1982.

[5] D. M. Kerns and R. W. Beatty, Basic Theory of Waveguide Junctions. New York: Permagon, 1967, p. 49.

[6] C. A. Hoer, "Performance of a dual six-port automatic network analyzer," IEEE Trans. Microwave Theory Tech., vol. MTT-27, pp. 993-998, Dec. 1979.

[7] N. T. Larsen, "A new self-balancing DC-substitution RF power meter," IEEE Trans. Instrum. Meas., vol. IM-25, pp. 343-347, Dec. 1976.

[8] G. F. Engen and C. A. Hoer, “Thru-reflect-line: An improved technique for calibrating the dual six-port automatic network analyzer," IEEE Trans. Microwave Theory Tech., vol. MTT-27, pp. 987-993, Dec. 1979.

[9] D. A. Hill, "Bandwidth limitations of TEM cells due to resonances," submitted to $J$. Microwave Power.

[10] F. M. Greene, "Measurement of RF power-absorption in biological specimens (10 to $100 \mathrm{MHz}$ )," NBS Tech Note 687, pg. 23, Nov. 1976.

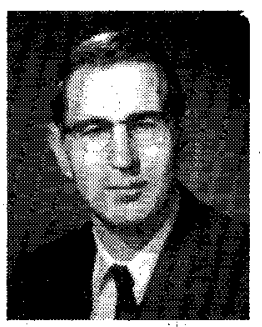

John R. Juroshek was born in Sheridan, WY, on January 7, 1940. He received the B.S. and M.S. degrees in electronic engineering from the University of Wyoming, Laramie, in 1961 and 1962, respectively. In 1966, he attended the University of California, Berkeley, for a year of postgraduate study in communications theory.

From 1962 to 1963, he was employed with the Federal Aviation Agency. In 1963, he joined the staff of the Department of Commerce at Boulder, $\mathrm{CO}$. Since that time, he has worked with the 
Institute of Telecommunication Sciences and the National Bureau of Standards in various areas of communications, antenna research, propagation research, and system design. His present interests are in automated systems and automated network analyzers.

Cletus A. Hoer was born in Westphalia, MO in 1933. He attended Weber State College, Ogden, UT, and Sophia University, Tokyo, Japan, while serving in the U.S. Air Force from 1950 to 1954 . He received the B.S. degree in engineering physics and the M.S. degree in electrical engineering, both from the University of Colorado, Boulder, in 1959 and 1967 , respectively.

He joined the Boulder Laboratories, National Bureau of Standards,

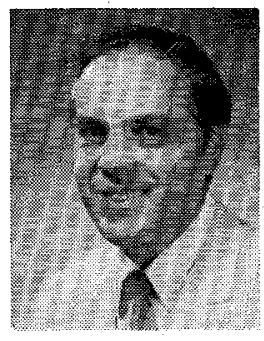

Boulder, CO, in 1956, where he was first engaged in developing instrumentation for measuring properties of magnetic materials at high frequencies. In 1962, he transferred to the High Frequency Impedance Standards Section, where he did research and development work on inductance standards, impedance bridges, inductive voltage dividers, attenuators, and directional couplers. In 1972, his emphasis shifted to developing Josephson junction detectors for precision RF attenuation measurements. Since 1974, he has been working on the theory and application of the 6-port concept to RF and microwave measurements. He and a coworker, Glenn Engen, received the Department of Commerce Gold Medal Award in 1976 for their development of the 6-port concept. He is the author or co-author of 36 technical papers and holds two patents.

\title{
Probing Electromagnetic Fields in Lossy Spheres and Cylinders
}

\author{
GARY H. WONG, STANISLAW S. STUCHLY, SENIOR MEMBER, IEEE, ANDRZEJ KRASZEWSKI, AND \\ MARIA A. STUCHLY, SENIOR MEMBER, IEEE
}

\begin{abstract}
Distributions of electric fields in lossy spheres and infinite lossy cylinders simulating biological objects were measured at 350,920, and $2450 \mathrm{MHz}$. The measurements were performed in a computer-controlled scanning system using three different implantable nonperturbing probes. The results are compared with theory, and use of lossy spheres and cylinders for calibration of implantable probes is quantitatively evaluated.
\end{abstract}

\section{INTRODUCTION}

$\mathrm{D}$ OSIMETRY OF electromagnetic fields is essential in quantifying biological effects of these fields and developing exposure standards for humans. Dosimetry is concerned with the determination of the electric-field intensity and the rate of energy deposition in biological bodies and their electrical models. The rate of energy deposition is defined as the specific absorption rate (SAR) usually expressed in $\mathrm{W} / \mathrm{kg}$ [1]. The SAR is directly related

Manuscript received October 12, 1983; revised March 8, 1984. This work was supported in part by grants from the Natural Sciences and Engineering Research Council of Canada and the U.S. Office of Naval Research.

G. H. Wong, S. S. Stuchly, and A. Kraszewski are with the Department of Electrical Engineering, University of Ottawa, Ottawa, Ontario, Canada K1N 6 N5

M. A. Stuchly is with the Radiation Protection Bureau, Health and Welfare Canada, Ottawa, Ontario, Canada. to the intensity of the electric field in situ and the electric properties of the tissue.

Considerable progress in theoretical and experimental dosimetric methods has taken place in recent years, as reviewed elsewhere [1]-[3].

Lossy dielectric spheres serve as convenient models of biological bodies and their parts [1]-[3]. These models are relatively easy to analyze theoretically and to construct for experimentation. They also provide adequate simulation of some biological systems under certain exposure conditions [1].

The distribution of electric fields in a lossy sphere was previously obtained theoretically [4], and a computer program was developed [5]. Qualitative experimental verification was obtained [6]; however, a quantitative analysis of the accuracy with which the electric-field distribution can be measured by implantable electric-field probes is wanting. The SAR distribution was also measured by the thermographic technique [7].

The electric fields in lossy cylinders were determined analytically for an infinite cylinder [8] and analytically and experimentally for cylinders of finite length [9]. In the latter case, the experimental technique used had serious limitations when used for cylinders of small diameters 